\title{
CREANDO EL MUSEO NACIONAL. EXPOSICIONES ARTÍSTICAS E IDENTIDAD EN LA JAMAICA POSTCOLONIAL
}

Data recepción: 2011/01/25

Carlos Garrido Castellano

Data aceptación: 2011/07/30

Universidad de Granada

Contacto autor: carlo_garrido@hotmail.com

\section{RESUMEN}

Este artículo pretende reconstruir lo que significó el proceso de independencia y construcción de la nación jamaicana a través del desarrollo de las instituciones de arte y el sistema expositivo del país. Para ello, se examinarán los principales elementos y problemas que gobernaron las políticas culturales jamaicanas posteriores a la Independencia, determinando el papel de los diferentes actores que intervinieron en las mismas, y poniéndolas en relación con el marco expositivo del arte caribeño contemporáneo tanto dentro como fuera de la región.

Palabras clave: Arte contemporáneo, Caribe, curadoría artística, Jamaica, National Gallery of Jamaica

\section{ABSTRACT}

This article aims to reassess the significance of the process of the independence and construction of the nation of Jamaica through the development of the country's art institutions and the system used to exhibit art. In doing so the article will analyse the main aspects and problems that conditioned cultural policies in Jamaica following independence. It will also detail the role of the various stakeholders involved and draw a link between them and the framework for exhibiting contemporary Caribbean art both in the region and outside it.

Keywords: Contemporary art, the Caribbean, art curation, Jamaica, National Gallery of Jamaica

\section{Introducción.}

\section{En torno a la problemática expositiva del arte jamaicano contemporáneo}

Se pretende en este artículo esbozar una cartografía del sistema expositivo del arte contemporáneo jamaicano desde el momento de la independencia hasta la década de los noventa, época de las grandes exposiciones internacionales de arte caribeño. En la categoría de arte contemporáneo jamaicano se incluirán no sólo el arte producido en la isla $-\mathrm{y}$ dentro de éste, como se verá, habría que señalar la existencia de ciertas peculiaridades, que establecen notables diferencias con respecto a la producción artística de otros países caribeños - sino también, en un sentido más amplio, la producción de los artistas de la diáspora, la exposición del arte jamaicano fuera de la isla, la gestión de centros expositivos alternativos al modelo de museo o galería, y, finalmente, la introducción de determinados elementos del arte internacional en el sistema expositivo de la isla. Con ello, se pretende arrojar luz a uno de los fenómenos más interesantes de la práctica artística caribeña y americana: Jamaica aparece como uno de los principales referentes en la generación y reinterpretación de valores simbólicos de toda la región caribeña, siendo frecuente la exportación de productos culturales - algo especialmente evidente en lo musical, pero que sobrepasa el ámbito de la música- como el ska, el mento, el reggae 0 , más recientemente, el dancehall'.

Como se irá apuntando, la internacionalización de la cultura jamaicana no se ha producido 
sino como simplificación de los conflictos culturales y sociales que tienen lugar en la isla, conflictos que son teorizados y repensados a través del funcionamiento de las industrias culturales. La necesidad de contextualizar la creatividad artística en el ámbito de éstas resulta acuciante por varias razones. La primera tiene que ver con la intensidad de las conexiones entre arte y sociedad en el caso jamaicano. A diferencia de lo que ocurre en otros territorios caribeños, el arte jamaicano contemporáneo se encuentra indisolublemente unido al devenir histórico de la isla. Baste señalar, como ejemplo, la vinculación de la que se considera la primera artista propiamente jamaicana, Edna Manley, con la evolución política de la nación².

Un segundo motivo estriba en que los textos sobre arte jamaicano elaborados desde el exterior, notablemente escasos, apenas se han centrado en el análisis contextualizado de la práctica artística, integrada en una realidad social dada ${ }^{3}$. Como consecuencia de ello, el arte jamaicano siempre es fetichizado y reducido a un cúmulo de estereotipos, entre los que sobresalen por su frecuencia y también por su incomprensión, por este orden, el movimiento rastafari, la violencia, lo festivo y las políticas de lo racial ${ }^{4}$. Además, es preciso señalar que dichos estereotipos sobre la cultura jamaicana son formulados no tanto a partir de la producción artística que se queda en las fronteras de la isla, sino a partir de la que sobrepasa esas fronteras y que consigue integrarse en el sistema referencial global.

Algo similar cabría decir si atendemos al peso de las artes visuales en el conjunto de la cultura jamaicana. Así, existe una fuerte desproporción entre la música y el arte. A primera vista podría considerarse algo lícito y normal, teniendo en cuenta la extraordinaria potencia musical jamaicana ${ }^{5}$. De hecho, una de las visiones más recurridas es la que hace de Jamaica una patria de músicos, capaz de exportar con asombrosa frecuencia productos culturales de incalculable valor al resto del mundo. Si bien esa posición se mantiene en la actualidad, algunas propuestas están empezando a orientar su mirada de los productos y su difusión al funcionamiento de las industrias culturales y a su inserción en el todo social jamaicano. Partiendo de esta posición, la desproporción entre arte y música deja de ser algo natural para convertirse en uno de los objetivos prioritarios de la crítica cultural jamaicana, dado que, aun cuando los resultados del funcionamiento de las industrias culturales vinculadas al arte es cuantitativamente inferior al musical ${ }^{6}$, la creatividad visual constituye un gran indicador de los procesos culturales que tienen lugar en el país?. Por otro lado, la reflexión crítica sobre el arte jamaicano apenas resulta evidente fuera de la isla. Hasta el momento, la producción bibliográfica apenas sale de Jamaica, quedando concentrada en medios de difusión locales $^{8}$, o bien en medios internacionales, cuya difusión en el medio académico jamaicano no resulta todo lo adecuada que debiera ser ${ }^{9}$. Además de ese aislamiento hay, por tanto, una desconexión entre ambas realidades.

Se impone, entonces, el llevar a cabo una revisión profunda del sistema expositivo jamaicano, verdadero motor de la producción artística del país y elemento dialogante, transformativo, generador y refractario a un tiempo de la cultura jamaicana. La presencia del arte jamaicano contemporáneo en el mundo de habla hispana ha sido mínima, si se exceptúan algunas participaciones en bienales y eventos artísticos internacionales celebrados en el Caribe hispanohablante y en Iberoamérica ${ }^{10}$; sin embargo, la calidad de las propuestas artísticas jamaicanas, la precisión con que permiten un acercamiento a la situación social y cultural de la región caribeña, y, por último, la creciente presencia española en la isla, que se manifiesta tanto en lo económico como en lo cultural ${ }^{11}$, urgen a un estudio en profundidad de la práctica artística jamaicana. Este artículo se concibe como una primera, y por fuerza incompleta, aproximación en esa línea.

\section{Análisis del sistema artístico jamaicano poscolonial: 1962-1990}

El arte jamaicano que encontraremos a partir de la década de los noventa es el producto de la culminación de propuestas artísticas que se remontan a un momento anterior a la Independencia del país. Esa tradición presenta dos líneas contrapuestas: una, que enlaza con un sistema de educación artística clásica establecido 
por el gobierno inglés, tiene a Isaac Mendes Belisario y a Edna Manley como principales referentes; la otra es la que definen los Intuitivos. En segundo lugar, las influencias externas de un sistema artístico que pese a estar orientado hacia una sociedad nacional, presenta claras conexiones con lo que sucede en la región caribeña y en el resto del mundo. Quizá el ejemplo más claro de esa vinculación con el ámbito artístico internacional sea el caso de David Boxer, quien llegó incluso a trabajar conjuntamente con Francis Bacon. La influencia del maestro irlandés será un motivo recurrente en la obra de Boxer, que, como la de aquél pero mostrando al mismo tiempo una personalidad arrolladora, aparece cargada de reminiscencias clasicistas vinculadas con un expresionismo consciente de la posición desde la que habla el artista ${ }^{12}$. Sin embargo, el caso de Boxer destaca por lo excepcional. Aunque existen otros casos - Poupeye menciona los de Karl Parboolsingh, formado con Fernand Léger y David Siqueiros, y Gloria Escoffery ${ }^{13}$ - la evolución del arte jamaicano seguirá los dos caminos anteriormente señalados. Edna Manley, cuya llegada al país se hace coincidir con el inicio de la modernidad artística en Jamaica ${ }^{14}$, pronto creará una fecunda escuela de pintores y escultores en la que es posible incluir a Albert Huie, David Pottinger o Alvin Marriot $^{15}$. Negro Aroused, la escultura que se convertirá en el símbolo del arte jamaicano y de la reivindicación de los derechos de la población negra a un tiempo, generó una amplia gama de apoyos y complicidades, sirviendo como estímulo para la creación de un buen número de artistas y escritores jóvenes ${ }^{16}$.

El marco en el que se desarrolla la modernidad artística en la época post-independencia coincide con la actividad de la National Gallery of Jamaica. Fundada en 1974 a partir de la iniciativa del Institute of Jamaica, la National Gallery pasó a ocupar la antigua mansión colonial de Devon House, situada cerca de la zona de Halfway Tree. En 1982, en que fue trasladada al Waterfront de Downtown Kingston, pasando a desempeñar una labor destacada en las acciones encaminadas a lograr la rehabilitación del barrio marítimo de la capital jamaicana. Aunque el traslado se concibió como algo temporal, en la actualidad la National Gallery sigue ubicada en el Downtown. Al año de su fundación, en 1975, David Boxer volvía al país para hacerse cargo de la curadoría y la dirección de la National Gallery. Desde el momento de su fundación, uno de los principales objetivos de la National Gallery coincidiría con la definición de una identidad artística nacional. En un panorama marcado por la necesidad de articular una visión de la historia nacional acorde a los imperativos de la nueva nación, la National Gallery encaminó sus actuaciones a generar unos criterios reguladores que sirvieran de base a dicha visión. Veerle Poupeye ha explicado esa unión entre identidad nacional y funcionamiento de la institución refiriéndose a cómo ésta contribuyó decisivamente a la definición del gusto por los Intuitivos:

This articulation process was a necessary part of the early work of the National Gallery, which opened in 1974 and was mandated to document a national (and nationalist) Jamaican art history ${ }^{17}$.

A partir de 1974, por tanto, la identidad y el gusto artístico pasan a centrar las preocupaciones presentes en la gestión patrimonial de la creatividad visual jamaicana. Esa unión de arte y gusto nacional dará lugar, no obstante, a importantes tensiones en las décadas siguientes ${ }^{18}$, tensiones que se recrudecerán en momentos en los que la gestión pública de la cultura adquiere mayor visibilidad a nivel social, como ocurre en el caso de las exposiciones nacionales, o bien en los procesos de comisión de obras de arte público. Volviendo a la National Gallery, es preciso señalar que la implementación de los objetivos institucionales contó con el desarrollo de un amplio programa público que tiene en el Departamento de Educación su brazo ejecutor; así, al tiempo que se establecía una fuerte conexión con los medios a partir de la frecuente participación en la prensa local y en las publicaciones especializadas y, más recientemente, a través del activo blog de la institución, se intentaba trasladar el arte a las masas en un país donde la visión tradicional hacía de la plástica, a diferencia de la música o incluso en contraposición con ésta, un patrimonio reducido a una elite socio-cultural ${ }^{19}$. 


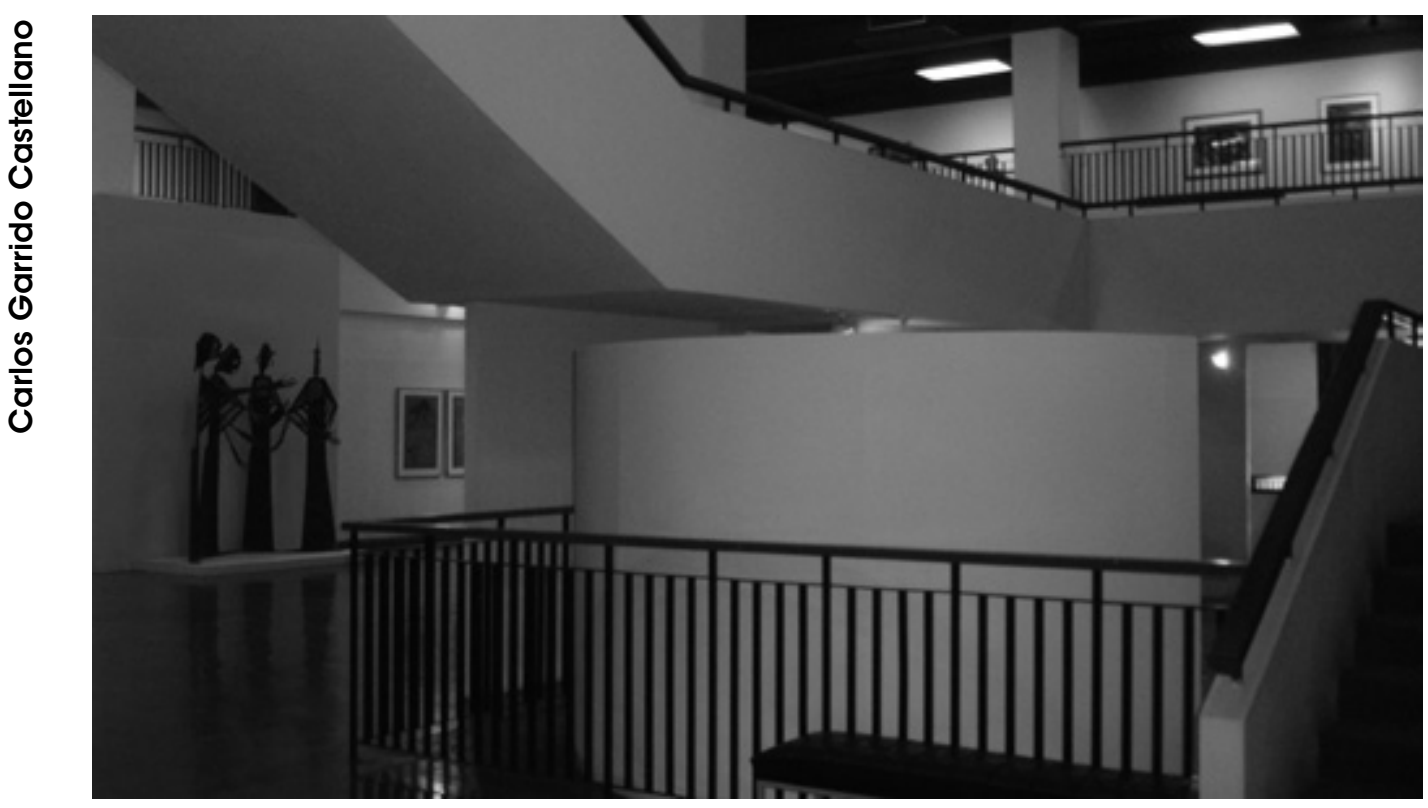

Fig. 1. National Gallery of Jamaica. Vista de la exposición permanente. Fotografía: Carlos Garrido.

Precisamente, la necesidad de ampliar el número de receptores a los que se dirigía el recién instituido museo que, no ha de olvidarse, representaba a la nueva nación, llevó a sus directores a trascender las limitaciones temporales marcadas por la fecha de la Independencia para trasladar el análisis del arte de la isla a periodos más tempranos.

Así, mediante la adquisición de obras, la reubicación del patrimonio artístico del Institute of Jamaica, institución a partir de la que nacía la National Gallery, se conseguía dar forma a la configuración de un sistema de exposición capaz de abarcar el arte precolombino, la producción cultural de los esclavos negros y el arte colonial2 $^{20}$. La National Gallery establecía una visión postcolonial del museo identitario jamaicano, visión que obligaba al público visitante a remontarse a los procesos históricos resultantes del encuentro entre africanos, europeos y americanos, y a la configuración de sociedades criollas. Quedaba articulada de este modo la exposición permanente del museo (Fig. 1), que incluía los restos de las primeras ciudades españolas, los resultados de la curiosidad de los primeros artistas viajeros, el reflejo del universo colonial británico y las primeras imágenes del proceso de independencia.

Se trata, por tanto, de un discurso postcolonial de tono antropológico, que busca contextualizar la obra de arte no sólo a partir de su relación con elementos de la economía y la sociedad del momento en que fue producida, sino también con los silencios, con los elementos subalternos de esos periodos. Así, por ejemplo, en la exposición actual pueden observarse elementos 


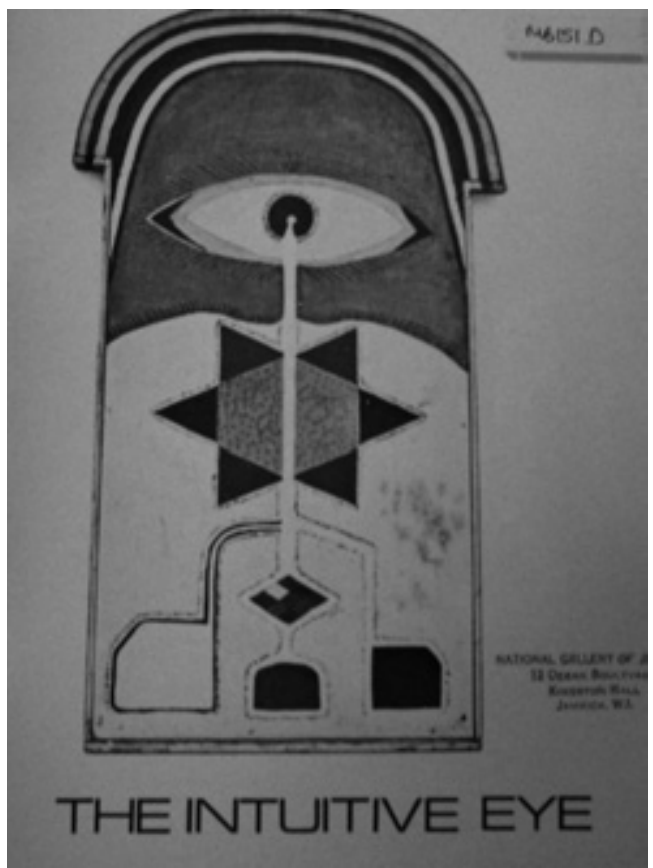

Fig. 2. Portada del catálogo de la exposición "The Intuitive Eye".

de tortura, utilizados por los dueños de las haciendas como medio de castigo de los esclavos insumisos, colocados al lado de visiones idílicas del paisaje cotidiano de la plantación. ¿Cuáles fueron las herramientas que permitieron que una institución pública, gubernamental, diera respuesta a las cuestiones identitarias de un país plural y recién creado como Jamaica? ¿Quedó algún elemento fuera del imaginario museístico nacional?

Quizá el caso más claro de la voluntad de la National Gallery de articular la visión del arte jamaicano plural, formada a partir de dos vías principales, que mencionábamos al principio de este apartado, sea el de las políticas expositivas de los Intuitivos ${ }^{21}$. Ya desde un primer momento la definición de qué es un artista intuitivo se presenta problemática. Un artista intuitivo será el que carezca del lastre de una formación artística, el que sea autodidacta. El concepto, sin embargo, va mucho más allá, al incluir una fuerte carga ideológica ${ }^{22}$. En efecto, reemplazará a las ideas de Arte Naïf o Arte Primitivo, que en ese momento aparecían dominadas por una valoración negativa. Desde el primer momento, así, existe en el análisis y la exposición del Arte Intuitivo un interés por vincular dicha manifestación con una consideración positiva, con una imagen que superara la del artista primitivo. Podría decirse, incluso, que el Arte Intuitivo nace, al menos como movimiento, asociado a la necesidad de definir lo que es un artista intuitivo.

Ahora bien; no sólo el Arte Intuitivo queda vinculado, adquiere su razón de ser en la historia del arte jamaicano, a través de su exposición. La valoración que incluye su término lleva implícito una voluntad de definir los contornos de la posición que éste ocupa en el canon artístico nacional. Así, a través de las sucesivas exposiciones de Arte Intuitivo, así como de la participación de artistas considerados como tales en las muestras nacionales, lo Intuitivo pasará de ser algo marginal, apartado del camino del arte jamaicano, a constituir el ejemplo más representativo del mismo, a convertirse en icono nacional. El primer eslabón en este proceso aparece en un momento temprano. En 1979 David Boxer, curador jefe de la National Gallery, organiza la que será la primera muestra de Arte Intuitivo bajo el título de Intuitive Eye. El origen de la muestra es narrado por el propio Boxer en el catálogo de ésta (Fig. 2):

This exhibition grows out of a passionate interest on my part in the work of our Jamaican Primitives -an interest which began when, still a schoolboy, I saw a carving of an Angel by Kapo in the window of the Hills Galleries. I remember a hollowedout torso and a feeling of mystery that it generated in me - that this was something very special- something from another place - another time.[...] Returning to live in Jamaica, new discoveries awaited me. Dunkley was the first. I had long admired his works, but I had only known the three paintings in the collection of the Institute of 
Jamaica. [...] In the years since, my personal pantheon of Jamaican Primitives has grown ${ }^{23}$ (Fig. 3).

El relato de Boxer está lleno de elementos susceptibles de ser analizados. En primer lugar, sorprende lo personal del tono que da pie a la muestra. Es el descubrimiento personal, el interés indagador del curador lo que desemboca en la revalorización de los Intuitivos, algo que resulta cuanto menos curioso si se tiene en cuenta que ya en la década siguiente el Arte Intuitivo ocupará el papel central en la identidad artística jamaicana. A la hora de realizar una primera cartografía del inventario que formará el museo nacional, encontramos que el centro de dicho mapa se muestra esquivo. La labor iniciada por Boxer y la National Gallery en 1979 puede entenderse, entonces, como una misión arqueológica, en la que la interpretación habrá de correr paralela a otro proceso no menos importante: el de la búsqueda y la recuperación de "la cultura material" intuitiva. En todo caso, pese a encontrar elementos que confluyen en una visión del arte común, en la que la espiritualidad, la originalidad o la separación con respecto al mercado se muestran como motivos comunes, no encontramos una definición del Arte Intuitivo; más bien, se nos ofrece una visión aproximada en la que pueden ser incluidas realidades harto diversas ${ }^{24}$.

La autenticidad aparece, además, como un requisito en la creación intuitiva, sin que se explique claramente en qué consiste ni cuáles son los requisitos para conseguirla. Boxer distingue, así, entre el Arte Intuitivo, que parte de una espiritualidad sincera, y el "airport art" presente en todo el Caribe ${ }^{25}$. Sea como fuere, la realidad es que la evolución del Arte Intuitivo resulta inseparable de su exposición. No en vano, en Intuitives III, la última exposición celebrada hasta la fecha, el interés por encontrar una definición adecuada ha dado paso a una relación centrada en cómo el arte intuitivo ha sido expuesto con enorme éxito tanto dentro como fuera del país, alcanzando una amplia y favorable acogida entre el público ${ }^{26}$. Dicho de otro modo: si en 1979 lo Intuitivo era todavía un territorio por descubrir, que sólo algunos pocos alcanzaban a atisbar y aun menos a comprender, para 2006 el Arte Intuitivo se había convertido en una industria cultural. El Director Ejecutivo de la exposición, J. Greenland, reconocerá, sin embargo, que "The subject is not without debate" ${ }^{\prime 2}$, algo que retomaría Veerle Poupeye un año después en los siguientes términos:

The notion of Intuitive art is therefore best understood as a canon that holds a special and highly contested position in the broader artistic and cultural canons that are being negotiated in Jamaica and not just as a politically correct synonym for Primitive, Naïve, or Outsider.[...] The status of the Intuitive artists thus remains ambivalent, located in a no-man's land between high and low culture, in which they are not empowered to take control of their representation which remains dependent on the artistic establishment ${ }^{28}$.

Ahora bien; no todo el arte jamaicano que encontró acogida en el espacio expositivo de la National Gallery durante los setenta y ochenta se redujo al Arte Intuitivo o al arte académico, moderno, traído por Edna Manley. A comienzos de los sesenta los artistas comienzan a experimentar - siempre de manera controlada- con los lenguajes de la Modernidad. El surrealismo, de la mano de creadores como Colin Garland y bajo la influencia siempre presente de John Dunkley, hará acto de presencia ${ }^{29}$. De la multiplicidad de propuestas - es necesario reiterar: siempre dentro del abanico de posibilidades ofrecido bien por la Modernidad, bien por el lenguaje Intuitivo-, así como de la voluntad integradora de la institución pública, dan constancia la serie de exposiciones que bajo el nombre de Aspects I, /I y III -ésta última celebrada ya en los noventa - unieron bajo un mismo tema a artistas de varias generaciones, medios expresivos y posicionamientos artísticos ${ }^{30}$.

Igualmente, la instauración de un sistema de exposiciones nacionales estará cimentado bajo el mismo interés plural. Al igual que ocurrirá en otros países, el sistema de selección y de premiación de la Annual Exhibition sentará las 


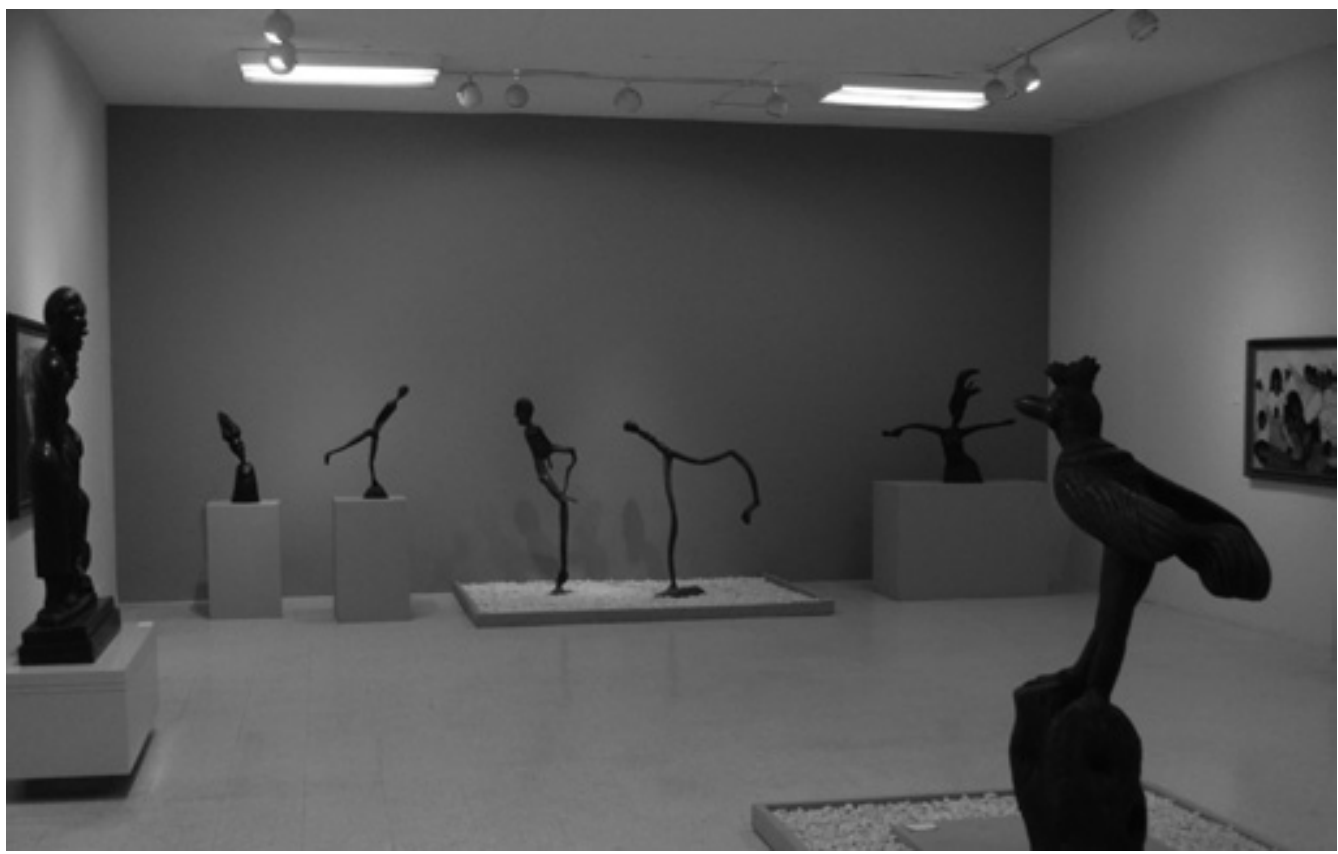

Fig. 3. National Gallery of Jamaica. Exposición temporal de Mallica Reynolds "Kapo". Fotografía: Carlos Garrido.

bases para la estabilización de la actividad artística en un país donde existían notables problemas en torno a la producción y la recepción artística. Las exposiciones anuales, por tanto, se convertían en un instrumento imprescindible en la articulación del sistema artístico nacional, como prueba la alta participación en todas las ediciones. Desde un primer momento se reconocerán como seleccionables los principales medios y lenguajes expresivos; asimismo, las muestras incluirán con frecuencia la obra de artistas residentes fuera del país. En 2002, por último, se producirá un cambio sustancial al adoptarse un formato de bienal acorde con los estándares artísticos internacionales ${ }^{31}$.

El periodo anterior a los noventa, momento de la gran expansión del arte jamaicano y caribeño, se cierra con dos acontecimientos de enorme trascendencia: la exposición Six Options: Gallery Spaces Transformed, celebrada en 1985, y la muestra itinerante Jamaican Art: 1922-1988. La primera suponía la irrupción de la instalación como medio expresivo y la superación de lo moderno en el arte jamaicano. Dentro de la exposición se encontraba la obra de Dawn Scott, A Cultural Object, que iba a romper el estatismo del sistema expositivo nacional con una propuesta totalmente novedosa. La radicalidad de la obra de Scott consiste en que aquélla consigue hacer que irrumpieran bruscamente la marginación y la miseria de las zonas más pobres del país en el santuario de la cultura de elite, rompiendo así el espejismo representacional desarrollado por el museo. El visitante era adentrado - a la entrada figuraba la siguiente leyenda: "Culture zone, enter at your own risk" - en un universo sobrecargado de mensajes que aludían a la realidad urbana de Kingston, y que dejaban traslucir la magnitud de la conflictividad social presente en la ciudad. Situándose en la frontera entre la provocación y la documentación de la realidad, A Cultural Object planteaba un reto notable a los preceptos establecidos en la fundación de la National 
Gallery; la obra, pese a encontrar respuestas negativas y a dar lugar a previsibles escándalos, pronto adquirió un aura especial, convirtiéndose en uno de los espacios más populares del museo. Al mismo tiempo se iniciaba un proceso de reapropiación más que singular:

While A Cultural Object obviously resonates with Jamaican audiences, the public response has always had a sensationalist, anarchic edge. Visitors almost immediately started adding their own graffiti to the walls and while the artist initially accepted this de facto interactivity, the results have been unexpected and often disturbing. Most of the graffiti are simply juvenile -of the "Kilroy was here" variety - but many others are obscene or politically partisan and illustrate exactly those cultural attitudes Scott sought to critique. Even the "street person" sculpture has been vandalized [...] and the at times unpleasant smell illustrates that some even urinate inside the installation ${ }^{32}$.

La otra gran exposición de los ochenta fue Jamaican Art:1922-1982, una muestra conmemorativa coorganizada por la National Gallery y el Smithsonian Institute. Pese a que se habían llevado a cabo retrospectivas individuales, era la primera vez en que se desarrollaba una revisión general del arte jamaicano. La muestra sirvió, además, para recuperar y poner en valor una gran cantidad de obras que habían permanecido hasta el momento desconocidas. Por otro lado, era la primera vez que el arte jamaicano, concebido como el producto de una evolución, salía fuera de las fronteras de la isla. Jamaican Art entroncaba, así, con una realidad que por entonces se atisbaba y que terminaría por centrar las preocupaciones - no sólo artísticasdel pensamiento jamaicano; a saber: que las comunidades existentes fuera del país, y el tráfico de ideas y de imágenes entre lo interior y lo exterior alcanzarían un protagonismo más que notable. Jamaican Art, así, elaboraba una visión que empezaba, contradiciendo a las fechas que señalaba el título, por la llegada de los españoles a la isla, y que culminaba con los últimos Intuitivos y las generaciones que despuntaron a principios de los ochenta.
Si el desarrollo de la actividad llevada a cabo por la National Gallery serviría para dar forma al "museo nacional", su labor se complementaría con la de la Edna Manley School of Visual \& Performing Arts, más conocido como Edna Manley College, nombre que recibe en 1995 en honor a la escultora. Fundada en una fecha tan temprana como 1950, la escuela será un factor clave en la democratización del arte jamaicano a finales del siglo XX; además, brindará un espacio para el debate, ya que muchos de los principales artistas del país —-Petrona Morrison, Margaret Chen, Omari Ra, Winston Campbell, Stanford Watson, Khalfani Ra-, así como un buen número de artistas jóvenes con una carrera sólida - Kericee Fletcher, Paula Daley-y de críticos e historiadores del arte -Petrina Dacresserán profesores de la escuela. Se trata, por tanto, del único centro universitario destinado a la enseñanza artística en el país, algo que lo convertirá en una institución clave para entender la irrupción de propuestas harto personales por parte de artistas jóvenes en los noventa. Por otro lado, la concepción de la escuela, en la que conviven estudiantes de música, artes escénicas, danza y estudios patrimoniales en un mismo recinto, concebido arquitectónicamente para fomentar los intercambios, supondrá un gran aliciente a la creatividad.

Además del Edna Manley College y de la National Gallery, apenas encontramos otras instituciones que lleven a cabo políticas expositivas coherentes y continuadas. Así, si bien en los ochenta aparece un buen número de galerías, ninguna sobrevivirá a los noventa ${ }^{33}$. Existe, no obstante, una notable excepción: la Mutual Life Gallery, creada en 1975 por la Mutual Life Insurance Company. La galería, asociada a la gran compañía aseguradora, desarrollará en sus primeros diez años una actividad orientada mayoritariamente a la venta, si bien a finales de los ochenta, coincidiendo con la dirección de Gilou Bauer, se convertirá en uno de los espacios de exposición para artistas jóvenes más deseados del país, así como en el segundo centro expositivo del país por detrás de la National Gallery. Desde ese momento, las exposiciones de la Mutual Life Gallery suelen atraer records de público, incluir la publicación de catálogos en color, y gozar de una amplia difusión en el 
ámbito nacional y en los circuitos del arte del Caribe anglófono ${ }^{34}$.

\section{Conclusiones}

Si se quisiera elaborar una valoración general de lo que supusieron las primeras décadas de funcionamiento de la National Gallery y del sistema artístico jamaicano, sería preciso señalar que ahora se consolida una sociedad receptora y productora de fenómenos artísticos, situación que dará como resultado el mantenimiento de un sistema regulador que luego quedará pequeño para la realidad artística. Precisamente, la relación con el Kitsch, la superación de la Modernidad y la inclusión de la postmodernidad en los discursos oficiales, se mostrará como uno de los principales caballos de batalla a finales de los ochenta. Parecía que la doble vía establecida por los ejemplos de Edna Manley/Intuitivos no dejaba espacio para caminos alternativos, para bús- quedas que se extendieran por paisajes más personales, o bien por la vía de la denuncia radical del sistema. Ese conflicto quedará como una de las principales herencias que encuentra el arte jamaicano en los noventa. Entre los principales temas por resolver a finales de los ochenta se encontraba la falta de visibilidad de algunas propuestas; la desconexión con la esfera artística caribeña; el carácter reducido del público artístico; o la creación de un establishment cultural encargado de discernir en torno a la inclusión y la exclusión de discursos.

Futuros estudios habrán de completar lo expuesto hasta ahora, contextualizándolo en el ámbito de la difusión de las culturas artísticas caribeñas contemporáneas, y rastreando los vínculos entre la cultura artística nacional postindependencia y las últimas décadas de dominio inglés, así como entre dicha época y las décadas de los noventa y dos mil.

\section{BIBLIOGRAFÍA}

AA.VV. (2006) Boxer at 60's. Kingston, Seaview Art Gallery.

AA.VV. (1995) In Tribute to David Boxer. Kingston, National Gallery of Jamaica.

Boxer, David (1990). Edna Manley: Sculptor. Kingston, Edna Manley Foundation; National Gallery of Jamaica.

Boxer, David (1987) Fifteen Intuitives. Kingston, National Gallery of Jamaica.

Boxer, David (1976) Five Centuries: Art in Jamaica since the Discovery. Kingston, National Gallery of Jamaica.

Boxer, David (2006) Intuitives III. Kingston, National Gallery of Jamaica.

Boxer, David (1979) The Intuitive Eye. Kingston, National Gallery of Jamaica.

Boxer, David y Poupeye, Veerle (1982) Jamaican Art 1922-1982. Kingston, National Gallery of Jamaica y Smithsonian Institution.

Boxer, David y Poupeye, Veerle
(1998). Modern Jamaican Art. Kingston, Ian Randle Publishers.

Cooper, Carolyn (2004) Sound Clash: Jamaican Dancehall Culture at Large. Nueva York, Palgrave MacmiIlan.

Dacres, Petrina (2009) " "But Bogle Was a Bold Man": Vision, History, and Power for a New Jamaica" Small Axe, 28, pp. 112-134.

Dacres, Petrina (2004) "Monument and Meaning" Small Axe, 16, pp. 137-153

Douglas, Andrea N. (2004) "Facing the Nation: Art History and Art Criticism in the Jamaican Context." Small Axe 8 (2), 49-60.

Edwards, Nadi (1998) "States of Emergency: Reggae Representations of the Jamaican Nation State." Social and Economic Studies, 47 (1), pp. 21-32.

Greenland, Jonathan (2006) "Foreword", en Boxer, David. Intuitives III. Kingston, National Gallery of Jamaica, p.3.

Hope, Donna P. (2006) Inna di Dancehall. Popular Culture and the Po- litics of Identity in Jamaica. Kingston, UWI Press.

Manuel, Peter (1992) Caribbean Currents. Caribbean Music from Rumba to Reggae. Philadelphia, Temple University Press.

National Gallery of Jamaica (1983) Aspects I. Kingston, National Gallery of Jamaica.

National Gallery of Jamaica (1991) Aspects III. Eight Jamaican Avant Garde Artists. Kingston, National Gallery of Jamaica.

National Gallery of Jamaica (2002) Jamaica National Biennial.2002. Kingston, National Gallery of Jamaica.

Paul, Annie (1997) "Pirates or Parrots? A Critical Perspective on the Visual Arts in Jamaica" Small Axe 1, 49-65.

Poupeye, Veerle (2009) "Dawn Scott's A Cultural Object" Entrada en el blog de la National Gallery of Jamaica [En línea]. http://nationalgalleryofjamaica.wordpress.com/2009/12/07/da wn-scotts-a-cultural-object/

Poupeye, Veerle (2007) "Intuitive Art as Canon" Small Axe, 24, pp.73-82. 


\section{NOTAS}

${ }^{1}$ La contribución de las industrias culturales jamaicanas a la producción y difusión de productos musicales aparece como uno de los fenómenos de difusión más importantes del continente americano. Existe una amplia bibliografía sobre cada uno de los estilos musicales originarios de Jamaica. Una perspectiva general en Manuel, Peter (1992) Caribbean Currents. Caribbean Music from Rumba to Reggae. Philadelphia: Temple University Press. En torno al dancehall ha surgido en los últimos diez años un profundo debate cultural. Véase al respecto Hope, Donna P. (2006) Inna di Dancehall. Popular Culture and the Politics of Identity in Jamaica. Kingston, UWI Press; o también Cooper, Carolyn (2004) Sound Clash: Jamaican Dancehall Culture at Large, Nueva York, Palgrave Macmillan.

${ }^{2}$ Sobre la importancia de la obra de Edna Manley en la definición de los discursos artísticos jamaicanos, véase Boxer, David (1990). Edna Manley: Sculptor. Kingston, Edna Manley Foundation; National Gallery of Jamaica.

3 Véase Douglas, Andrea N. (2004) "Facing the Nation: Art History and Art Criticism in the Jamaican Context." Small Axe 8 (2), 49-60; Paul, Annie (1997) "Pirates or Parrots? A Critical Perspective on the Visual Arts in Jamaica" Small Axe 1, 49-65.

${ }^{4}$ Krista Thompson ha acertado a elaborar un agudo análisis de la influencia de estos estereotipos. Véase Thompson, Krista (2006) An Eye for the Tropics. Tourism, Photography, and Framing the Caribbean Picturesque. Durham, Duke University Press.

${ }^{5}$ Para una revisión comparativa de la evolución de música y artes visuales, véase Boxer, David y Poupeye, Veerle (1998). Modern Jamaican Art. Kingston, Ian Randle Publishers.

${ }^{6}$ En la práctica, sin embargo, resulta imposible establecer la frontera entre ambas manifestaciones. La visualización de lo musical y el papel de la imagen asociada a la música como elemento configurador de espacios ur- banos; la producción de un amplio merchandising indisolublemente ligado a lo icónico y la performatividad, hacen que el fenómeno musical exista sola y exclusivamente en conexión con la imagen.

${ }^{7}$ Véase al respecto los capítulos dedicados al análisis de la raza y la identidad en el volumen sobre arte caribeño escrito por Veerle Poupeye. Poupeye, Veerle (1998) Caribbean Art. Londres, Thames \& Hudson.

${ }^{8}$ Entre los que cabe señalar, en primer lugar, la edición de catálogos por parte de las instituciones artísticas oficiales; y, en segundo, la publicación de revistas especializadas, como Jamaica Journal, por parte de la University of the West Indies.

9 Pese al perfeccionamiento de los cauces de difusión utilizados por la crítica cultural jamaicana, existe una notable desconexión entre la práctica artística insular y la difusión y recepción de los productos del aparato críti$\mathrm{co}$, orientados principalmente al sector académico internacional. Pese a ello, la actividad de algunos críticos, como Petrine Archer o Annie Paul en el medio digital, así como la inserción de la National Gallery of Jamaica en dicho medio, ha contribuido a un acercamiento entre crítica y arte.

${ }^{10}$ Dejando a un lado las exposiciones celebradas por Cariforum, iniciativa que surge en los noventa auspiciada por la Unión Europea y que desarrolla varias muestras itinerantes de pintura y dibujo en las que participan artistas jamaicanos, la Bienal de la Habana, evento en el que encontramos propuestas de artistas jamaicanos desde su fundación, constituye la única excepción a dicha ausencia.

${ }^{11}$ En una entrevista inédita con el Embajador de España en Jamaica pudimos corroborar cómo la presencia española en la cultura jamaicana se ha incrementado en los últimos diez años, lo cual se ha traducido en el desarrollo de campañas de conservación y difusión patrimonial, como la que tiene lugar desde hace unos años en el casco histórico de la primera capital in- glesa en la isla, la ciudad de Spanish Town; o bien en la celebración de hasta cuatro exposiciones de artistas contemporáneos españoles.

${ }^{12}$ Boxer es quizá el artista jamaicano de todos los tiempos con una trayectoria más interesante, además de una figura clave en la institucionalización del arte jamaicano, algo que pudimos comprobar mediante una entrevista con el artista y curador. Sobre su obra véase AA.VV. (1995) In Tribute to David Boxer. Kingston, National Gallery of Jamaica; AA.V. (2006) Boxer at 60's. Kingston, Seaview Art Gallery.

${ }^{13}$ Poupeye, Veerle (1992) "Voix et visions: les arts plastiques en Jamaique" en Bocquet, Pierre (Ed.) 14921992. Un nouveau regard sur les Caraïbes. París, Creolarts, p.114.

${ }^{14}$ Boxer, David y Poupeye, Veerle (1982) Jamaican Art 1922-1982. Kingston, National Gallery of Jamaica y Smithsonian Institution, p.10.

${ }^{15}$ Poupeye, Veerle (1992) "Voix et visions: les arts plastiques en Jamaique" en Bocquet, Pierre (Ed.) 1492 1992. Un nouveau regard sur les Caraïbes. París, Creolarts p.111.

${ }^{16}$ Negro Aroused constituye el primer hito de la historia del arte público en Jamaica. Las cuestiones relacionadas con la representación y la gestión del espacio urbano han ocupado el interés de la crítica en la última década, generando un clima de debate basado en la definición de la identidad nacional y en la negociación entre la "alta cultura" y lo popular. Véase al respecto los trabajos de Petrina Dacres: Dacres, Petrina (2004) "Monument and Meaning" Small Axe, 16, pp. 137-153; Dacres, Petrina (2009) " "But Bogle Was a Bold Man": Vision, History, and Power for a New Jamaica" Small Axe, 28, pp. 112-134.

${ }^{17}$ Poupeye, Veerle (2007) "Intuitive Art as Canon" Small Axe, 24, p. 74

18 Las "guerras culturales" que dominarán el panorama jamaicano durante las décadas de los ochenta y noventa, para suavizarse en los dos mil, estarán marcadas por criterios relacionados con los procesos de selección e 
inclusión de artistas, las políticas de apreciación del arte popular por parte de un público que constituye una elite cultural o la representatividad de las políticas curatoriales llevadas a cabo por la National Gallery. Véase al respecto Wainwright, Leon (2005) "Art and Inclusion at Jamaica's National Gallery: The 2004 National Biennial" Jamaica Journal, 29 (1-2), pp. 18-26; y Edwards, Nadi (1998) "States of Emergency: Reggae Representations of the Jamaican Nation State." Social and Economic Studies, 47 (1), pp. 21-32.

${ }^{19}$ Eso es algo que todavía es reprochado a la institución; sin embargo, conviene señalar que, como pudimos comprobar, la actividades orientadas a la difusión desarrolladas por la National Gallery ocupan el primer lugar en los programas del centro.

${ }^{20}$ Exposiciones como Five Centuries: Art in Jamaica since the Discovery, celebrada en 1976, atestiguan la presencia de esa voluntad de elaborar una explicación "tricontinental", basada en un proceso largo, del arte jamaicano desde el nacimiento de la institución. Véase catálogo de la exposición.

${ }^{21}$ Desde la Independencia ha habido tres exposiciones de arte intuitivo: The Intuitive Eye (1979), Fifteen Intuitives (1987) e Intuitives III (2006). Los textos que acompañaron a los catálogos de las muestras permiten observar cómo tanto la definición teórica del concepto "Intuitivo" como su aplicación práctica responde a una evolución vinculada a los criterios expositivos de la National Gallery. Véanse catálogos.

${ }^{22}$ Poupeye, Veerle (2007) "Intuitive Art as Canon" Small Axe, 24, pp.73-82.
${ }^{23}$ Boxer, David. (1979) The Intuitive Eye. Kingston, National Gallery of Jamaica, p.2. El subrayado es nuestro. Nótese cómo todavía en este primer momento aparece el término "Primitive", algo que ha sido apuntado también por Veerle Poupeye. Véase Poupeye, Veerle (2007) "Intuitive Art as Canon" Small Axe, 24, pp.73-82.

24 "These artists paint, or sculpt, intuitively. They are not guided by fashion. Their vision is pure and sincere, untarnished by art theories and philosophies, principles and movements. They are for the most part, selftaught. Their visions (and many are true visionaries) as released through paint or wood, are unmediated expressions of their individual relatinoships with the world around themand the worlds within. Some of them-Kapo, Everald Brown, William Joseph in particular-reveal as well a capacity for reaching into the depths of the subconscious to rekindle century old traditions, and to pluck out images as elemental and vital as those of their African fathers." Boxer, David. (1979) The Intuitive Eye. Kingston, National Gallery of Jamaica, p.2.

25 "It is a school of authentic creators whose works have nothing to do with the pseudo-primitive, or more specifically, the pseudo-African that approaches Kitsch, the so-called "airport art" which we find, not only in Jamaica, but in every island across the Caribbean." Ibid., p.2.

${ }^{26}$ Greenland, Jonathan (2006) "Foreword", en Boxer, David. Intuitives III. Kingston, National Gallery of Jamaica, p.3.

27 Greenland, Jonathan (2006) "Foreword", en Boxer, David. Intuiti- ves III. Kingston, National Gallery of Jamaica, p.3.

${ }^{28}$ Poupeye, Veerle (2007) "Intuitive Art as Canon" Small Axe, 24, pp. 79-80.

${ }^{29}$ Una visión panorámica del arte jamaicano post-independencia en Archer-Straw, Petrine (ed.) (2000) Fifty Years, Fifty Artists, 1950-2000: The School of Visual Arts. Kingston, lan Randle Publishers y Edna Manley School of Visual \& Performing Arts.

${ }^{30}$ Véanse catálogos de las exposiciones.

31 National Gallery of Jamaica (2002) Jamaica National Biennial.2002. Kingston, National Gallery of Jamaica.

32 Poupeye, Veerle (2009) "Dawn Scott's A Cultural Object" Entrada en el blog de la National Gallery of Jamaica. [En línea]. http://nationalgalleryofja maica.wordpress.com/2009/12/07/da wn-scotts-a-cultural-object/

33 Robinson, Kim (1991) "New Art Galleries" Jamaica Journal, 24 (1), pp. 38-49.

${ }^{34}$ En una entrevista, la actual directora, Gilou Bauer, nos explicaba el proceso de fundación de la galería en los siguientes términos: "They had given that space to artists to have exhibitions. At first they wanted to give it to the Guild of Artists but they did not do a good job of it, so eventually they got somebody else to work in the gallery, actually was somebody very commercial, that being commercial she made a lot of sales increasing the interest in the arts, not so much in terms of the type of art, she was not so interested in why the artists are working, but she was interested in sales." Entrevista con Gilou Bauer. Documento inédito. 